\title{
COMMENTARY
}

\section{Renal replacement therapy: to treat, or not to treat, that is the question...}

\author{
Michael Joannidis ${ }^{1 *}$ and Lui G Forni \\ See related research by Clec'h et al., http://ccforum.com/content/16/6/R236 and related research by Thakar et al., \\ http://ccforum.com/content/16/6/R237
}

\begin{abstract}
When to commence renal replacement therapy (RRT)

in the critically ill remains an unresolved issue. The

study by Thakar and colleagues sheds some light

on current practice through an international survey,

demonstrating physicians' inclination to start RRT

earlier when the severity of disease is higher. However,

Clec'h and co-workers investigated the effect of RRT on

hospital survival by performing a propensity analysis on

the large multicentre French OUTCOMEREA database.

They demonstrate that RRT does not confer survival

benefit, with a delay in initiation being proposed as a

contributing factor.
\end{abstract}

Timing of initiation of renal replacement therapy (RRT) is currently one of the major unresolved topics in critical care nephrology and this is addressed through different approaches in a previous issue of Critical Care [1,2]. Thakar and colleagues [1] performed an international survey predominantly among North American nephrologists consulting in intensive care. They questioned practice patterns for the initiation of RRT using three case scenarios representing patients with increased severity of disease and, by implication, a higher probability of mortality. The majority of the 172 respondents (70\% USA) expressed a reticence in commencing RRT early given the lack of evidence, preferring to base their decision on absolute levels of creatinine or blood urea nitrogen $(\mathrm{BUN})(>442 \mu \mathrm{mol} / \mathrm{l}(>5 \mathrm{mg} / \mathrm{dl}),>35.6 \mathrm{mmol} / \mathrm{l}$ (>100 $\mathrm{mg} / \mathrm{dl})$, respectively) rather than any relative rise. Despite this, $94 \%$ of physicians reported that they would be likely to start dialysis early in patients with the highest

*Correspondence: michael.joannidis@i-med.ac.at

'Medical Intensive Care and Emergency Unit, Department of Internal Medicine,

Medical University Innsbruck, Anichstrasse 35, 6020 Innsbruck, Austria

Full list of author information is available at the end of the article disease burden with early RRT described as a lower BUN on commencing treatment. Thus, the proportion of physicians starting dialysis at a BUN $<75 \mathrm{mg} / \mathrm{dl}$ tripled in the more severe case. Finally, given a selection of five parameters (BUN, creatinine, urine output, oxygenation and potassium) for starting RRT, the latter two were given the highest priority with oxygen saturation appearing as the most frequent trigger in severe cases. However, as in most studies of this nature, cohort selection is of great importance. For example, only two nephrologists were also trained in critical care. The responses were substantially influenced by current practice in the US underlined by the significantly higher inclination towards early initiation of RRT in physicians practicing outside the US [1]. These results also differ to a recently published survey among 275, mainly European intensivists [3]. Whereas the median thresholds with regard to serum creatinine $(300 \mu \mathrm{mol} / \mathrm{l})$ or urea $(40 \mathrm{mmol} / \mathrm{l})$ were similar, there was a higher priority attached to hyperkalemia, metabolic acidosis and volume overload. Additionally, they demonstrated a trend towards early initiation of RRT, with the majority favouring initiation when a diagnosis of acute kidney injury (AKI) was made based on AKIN (Acute Kidney Injury Network)/RIFLE (Risk, Injury, Failure, Loss, End-Stage Renal Disease) criteria, particularly with regard to oliguria [3]. Thus, early treatment was defined by starting RRT within 6 hours after AKI diagnosis according to the AKIN/ RIFLE criteria. The perceived importance of oliguria as a trigger for commencing RRT is supported by other studies. For example, the international BEST kidney study group identified oliguria/anuria as the most frequent reason to start RRT [4] and similar results were seen in the RENAL trial where oliguria was the indication to start in $60 \%$ of all patients [5].

A completely different approach towards initiation of treatment was chosen by Clec'h and co-workers investigating the effect of RRT on hospital survival in the French longitudinal prospective multicenter OUTCOMEREA database [2]. They addressed the question as to whether RRT confers a survival benefit in critically ill patients 
through sophisticated propensity analyses. Using two different propensity scores the answer was a resounding 'NO'. Do these results mean that RRT should be abandoned? Of course not: RRT definitely does one thing - it clears toxins and re-establishes electrolyte, acidbase and fluid homeostasis. Therefore, the maximum one could expect from provision of RRT would be hospital mortality equal to patients not requiring RRT. However, the occurrence of AKI reflects a higher severity of disease and is independently associated with increased mortality [6-8]. Therefore, observed outcome will always be worse, regardless of how efficiently we replace the failing kidneys. This is clearly supported by the significantly higher modified Severity of Organ Failure score (mSOFA) and Simplified Acute Physiology Score (SAPS) II scores found for patients treated with RRT in both the crude comparison and the two propensity models [2]. Interestingly, one of the main conclusions was to commence RRT earlier based on the finding that delayed RRT, that is, starting 48 hours after reaching maximum RIFLE, was associated with a two-fold increased odds ratio for mortality compared to early or immediate RRT. However, only $12 \%$ of all patients treated with RRT fell into the 'late' category and the median duration from onset of AKI to start of RRT was only one day in this cohort. So, although the data suggest that 'very late RRT' will be probably detrimental, no reliable conclusions can be drawn regarding the benefit of early or very early initiation of RRT from this study [2]. Lower stages of AKI are associated with a lower mortality; thus, it could be argued that one should not wait until the patient has reached a higher level of AKI before commencing treatment $[8,9]$. This is compounded by the fact that the maximum AKI stage remains a retrospective diagnosis and cannot be reliably predicted. Nor can patients who will progress to a stage where RRT will be absolutely necessary or those who will recover without the need for RRT [10]. In fact, three smaller randomized controlled trials showed either no benefit with early RRT $[11,12]$ or even an increased mortality compared to standard medical treatment in severe sepsis [13]. In trying to determine which parameter might be the most relevant for starting RRT, Clec'h and colleagues [2] found only oliguria $(0.4 \mathrm{~L}$ versus $1.3 \mathrm{~L}$ ) and fluid accumulation (4 L versus $2 \mathrm{~L}$ ) as significant for patients treated with RRT when performing a matched pair analysis. This again may reflect changes in practice in terms of avoiding a positive fluid balance.

The syndrome of AKI continues to gain importance; the numbers of AKI patients requiring RRT have roughly doubled over the past 10 years in the USA [14], which contribute to increased mortality and an increased burden on health care systems. Several surveys and clinical studies reveal significant variations in treatment patterns as well as outcomes, largely dependent on regional or national habits as well as the primary medical speciality delivering RRT in critically ill patients. The practice of using fixed thresholds of creatinine or urea for timing of RRT may be considered a relic from haemodialysis programmes where creatinine is taken as a surrogate for residual function [15]. In critically ill patients with AKI, urea and creatinine are not reliable indicators of renal function given the lack of steady state in terms of production and the influence of catabolism, volume status and production rates, particularly in sepsis [10]. Consequently, physicians treating critically ill patients put an increasing emphasis on volume overload, oliguria, impaired oxygenation and acidosis as triggers for initiation of RRT with a general trend to commence RRT earlier in sicker patients.

Despite some progress achieved by recent recommendations [16], no generally accepted consensus as to when to commence RRT exists. Probably the conventional criteria discussed above are not sufficient to discriminate between early and late initiation of RRT and including additional biomarkers indicating renal damage may be required for that. This, however, can only be answered by a future sufficiently powered prospective randomized controlled trial.

\section{Abbreviations}

AKI, acute kidney injury; AKIN, Acute Kidney Injury Network; BUN, blood urea nitrogen; RIFLE, Risk, Injury, Failure, Loss, End-Stage Renal Disease; RRT, renal replacement therapy.

\section{Competing interests}

MJ received speaker's and consulting honoraria from Baxter, Fresenius and Gambro. LGF reports no competing interests.

\section{Acknowledgement}

MJ and LGF drafted, wrote and proofread the manuscript.

\section{Author details}

'Medical Intensive Care and Emergency Unit, Department of Internal Medicine, Medical University Innsbruck, Anichstrasse 35, 6020 Innsbruck, Austria. ${ }^{2}$ Department of Critical Care, Western Sussex Hospitals Trust, Honorary Senior Lecturer, Brighton and Sussex Medical Schools, University of Sussex, Falmer, Brighton BN1 9PX, UK.

Published: 19 March 2013

\section{References}

1. Thakar CV, Rousseau J, Leonard AC: Timing of dialysis initiation in AKI in ICU: international survey. Crit Care 2012, 16:R237.

2. Clec'h C, Darmon M, Lautrette A, Chemouni F, Azoulay E, Schwebel C, Dumenil AS, Garrouste-Org, Goldgran-Toledano D, Cohen Y, Timsit JF: Efficacy of renal replacement therapy in critically ill patients: a propensity analysis. Crit Care 2012, 16:R236.

3. Legrand M, Darmon M, Joannidis M, Payen D: Management of renal replacement therapy in ICU patients: an international survey. Intensive Care Med 2013, 39:101-108.

4. Uchino S, Bellomo R, Morimatsu H, Morgera S, Schetz M, Tan I, Bouman C, Macedo E, Gibney N, Tolwani A, Oudemans-van SH, Ronco C, Kellum JA: Continuous renal replacement therapy: a worldwide practice survey. The beginning and ending supportive therapy for the kidney (B.E.S.T. kidney) investigators. Intensive Care Med 2007, 33:1563-1570.

5. Bellomo R, Cass A, Cole L, Finfer S, Gallagher M, Lo S, McArthur C, McGuinness 
S, Myburgh J, Norton R, Scheinkestel C, Su S: Intensity of continuous renalreplacement therapy in critically ill patients. N Eng/ J Med 2009,

361:1627-1638.

6. Joannidis M, Metnitz PG: Epidemiology and natural history of acute renal failure in the ICU. Crit Care Clin 2005, 21:239-249.

7. Metnitz PG, Krenn CG, Steltzer H, Lang T, Ploder J, Lenz K, Le Gall JR, Druml W: Effect of acute renal failure requiring renal replacement therapy on outcome in critically ill patients. Crit Care Med 2002, 30:2051-2058.

8. Joannidis M, Metnitz B, Bauer P, Schusterschitz N, Moreno R, Druml W, Metnitz PG: Acute kidney injury in critically ill patients classified by AKIN versus RIFLE using the SAPS 3 database. Intensive Care Med 2009, 35:1692-1702

9. Hoste EA, Clermont G, Kersten A, Venkataraman R, Angus DC, De BD, Kellum JA: RIFLE criteria for acute kidney injury are associated with hospital mortality in critically ill patients: a cohort analysis. Crit Care 2006, 10:R73.

10. Joannidis M, Forni LG: Clinical review: timing of renal replacement therapy. Crit Care 2011, 15:223.

11. Bouman CS, Oudemans-van Straaten HM, Tijssen JG, Zandstra DF, Kesecioglu $\mathrm{J}$ : Effects of early high-volume continuous venovenous hemofiltration on survival and recovery of renal function in intensive care patients with acute renal failure: a prospective, randomized trial. Crit Care Med 2002, 30:2205-2211.
12. Cole L, Bellomo R, Hart G, Journois D, Davenport P, Tipping P, Ronco C: A phase II randomized, controlled trial of continuous hemofiltration in sepsis. Crit Care Med 2002, 30:100-106.

13. Payen D, Mateo J, Cavaillon JM, Fraisse F, Floriot C, Vicaut E: Impact of continuous venovenous hemofiltration on organ failure during the early phase of severe sepsis: a randomized controlled trial. Crit Care Med 2009, 37:803-810.

14. Hsu RK, McCulloch CE, Dudley RA, Lo LJ, Hsu CY: Temporal changes in incidence of dialysis-requiring AKI. J Am Soc Nephrol 2013, 24:37-42.

15. Poggio ED, Wang X, Greene T, Van LF, Hall PM: Performance of the modification of diet in renal disease and Cockcroft-Gault equations in the estimation of GFR in health and in chronic kidney disease. J Am Soc Nephrol 2005, 16:459-466.

16. KDIGO Clinical Practice Guideline for Acute Kidney Injury. Kidney Int 2012, Suppl 2:1-138.

doi:10.1186/cc12535

Cite this article as: Joannidis M, Forni LG: Renal replacement therapy: to treat, or not to treat, that is the question.... Critical Care 2013, 17:125. 